\title{
A Review of Component and Pharmacology Activities of Black Garlic
}

\author{
Novitaria Sembiring1,2*, Yoppi Iskandar ${ }^{2}$ \\ ${ }^{1}$ Master Program of Pharmacy, Faculty of Pharmacy, Universitas Padjajaran, Sumedang, Indonesia \\ 2 Department of Biology Pharmacy, Faculty of Pharmacy, Universitas Padjajaran, Sumedang, Indonesia
}

\begin{abstract}
Black garlic is garlic fermented in high temperature and humidity, and the fermentation compound chemical in garlic changes to new chemicals, such as S-allyl cysteine (SAC), S-allylmercapto-cysteine, and arginine. The color changed to dark brown during the aging period because of the Maillard reaction, known as non-enzymatic browning reaction. Black garlic has $57.14 \%$ of fructose, $6.78 \%$ of glucose, and $7.62 \%$ of sucrose, which were mainly saccharides in black garlic to answer for its sweet taste. It is such a pharmacological activity which contains antioxidant, anti-cancer, hepatoprotective, can improve the immune system, reduce hyperglycemia, dyslipidemia, and anti-allergic. We summarize the current knowledge of a change in the components, bioactivity, production, and applications of black garlic, as well as the proposed future prospects on their possible applications as a functional pharmacy product.
\end{abstract}

Keywords: Antioxidant; Black garlic; Immune system; S-allyl cysteine;

\section{INTRODUCTION}

Indonesian had long consumed garlic as traditional medicine. For instance, the Baduy ethnic who consumes 3 cloves of garlic to treat high blood pressure. To deal with gout and rheumatism ethnic, Batak uses finely ground garlic with salt then rub on the affected part. In the ethnic of Talang Mamak, garlic gutters are used to treat diarrhea, while ethnics in Palembang uses garlic oil to cure abdominal pain, swollen flatulence, shortness of breath, vomiting, lumbago, miscarriage (Moelyono, 2004). Asian countries such as South Korea, Japan, and Thailand, has consumed black garlic as food for centuries, for it tastes sweeter, more jelly-like, and the odor is not like garlic.

Black garlic is fresh garlic fermented in high temperatures and humidity. It contains DL-Lactic acid, 5-hydroxymethyl-2-furfural, adenosine, uridine, (1S,3S)-1methyl-1,2,3,4-tetrahydro- $\beta$ carboline-3-carboxylic acid, (1R,3S)-1methyl1,2,3,4-tetrahydro- $\beta$-carboline-3-carboxylic acid, and 2-Acetylpyrrole, which have higher antioxidant (Lu et al., 2017). Concentration alliin content in the black garlic sample decreases because alliin converted into S-allyl cysteine (SAC), S-allylmercapto-cysteine, arginine, and other undefined compounds when subjected to thermal processing (Zhang et al., 2015). The amount of SAC in black garlic is generally five to six times higher than that in fresh garlic and is thought to have the beneficial effects of black garlic.

Pharmacological activities such as lowering cholesterol, anti-allergic, high antioxidant activity,

\footnotetext{
*Corresponding author : Novitaria Sembiring

Email : novitaria18001@mail.unpad.ac.id
}

can improve the immune system, inhibit HT29 cell growth in colon cancer, anti-tumor, reduce hyperglycemia, dyslipidemia, hepatoprotective, and induce apoptosis in cell human leukemia U937 (Tran et al., 2018). The main focus of this study is to summarize the current knowledge of the component of black garlic and activity pharmacology.

To cause extracellular matrix accumulation by enhancing the mesangial cell production of $\mathrm{COL}$ and FN, TGF- $\beta$ mediated fibronectin is expressed in mesangial cells (Uchiyama-Tanaka et al., 2002). Reactive Oxygen Species (ROS) also underlies as a common pathogenic component and accelerates kidney disease progression and complications (Dounousi et al., 2006). Soybean seed showed an antioxidant effect and an antifibrotic effect in the remnant kidney, which resulted in the improvement of the renal function. Oxidative stress is regulated by the balance between prooxidant and antioxidant systems (Peng et al., 2017; Hayata et al., 2012).

Soybean seed (Glycine max L. Merr) has been known for its beneficial effects in health due to its compounds. Previous studies reported that soybean contains antinutritional factors (ANF) which include lipase inhibitors, protease inhibitors, amylase inhibitors, oxalic acid, phytic acid, glucosinolates, flavonoid, and saponin. The ethanol extract of soybean also known to contain natural compounds such as flavonoid, phenolic, triterpenoid, saponin, steroid, tannin, and quinone (Gemede and Ratta, 2014). In this study, we used Glycine max L. merr ethanol extract (EEDS) to evaluate the potency for therapy chronic kidney disease due to the measure of cytotoxic effects, 


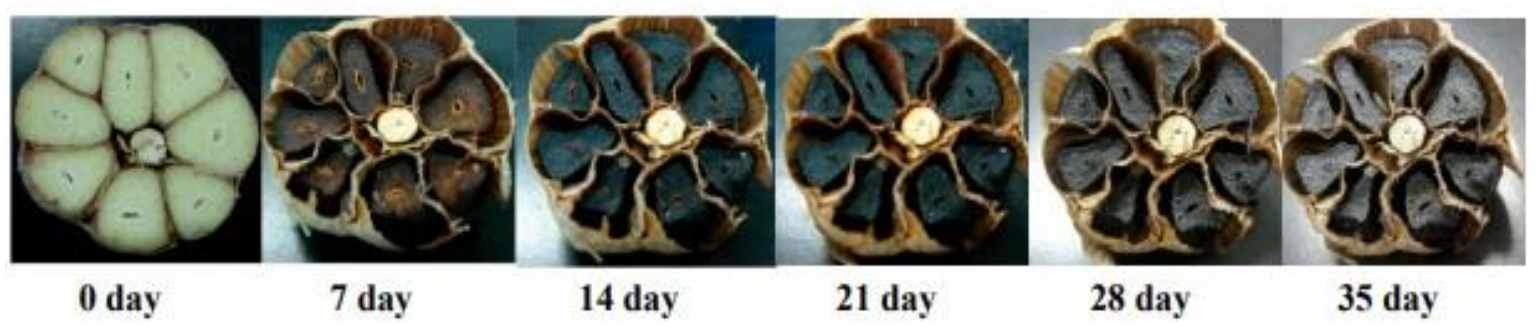

Figure 1. Change color of garlic during 35 days (Choi et al., 2014)

fibronectin, TGF- $\beta 1$, and ROS-DCFDA inhibition potential of EEDS on glucose-induced Mesangial cells (SV-40).

\section{Component of Black Garlic}

Color is one of the most important psychological properties of food products that affect the perception of eating in consumers, clarify how black garlic (BG) changes during the 35-day aging were evaluated under controlled conditions of $70^{\circ} \mathrm{C}$ and $90 \%$ relative humidity. Lightness and yellowness values of black garlic radically decreased during the aging period, whereas redness values increased significantly. The color of black garlic changed to dark brown during the aging period, whereas the $\mathrm{pH}$ decreased continually from 6.25 to 4.25 , which contributed a characteristic black appearance and a sour taste mouthfeel. Color changes and decrease of $\mathrm{pH}$ resulting from heat treatment are typically due to the Maillard reaction, known as non-enzymatic browning reaction. It is same with (Zhang et al., 2015), the contents of alliin and polysaccharides black garlic decreased significantly after 10 days of heat treatment heating at $70-80^{\circ} \mathrm{C}$ because of alliin content black garlic converted into SAC, Sallylmercapto-cysteine, arginine, and other undefined compounds when subjected to thermal processing, whereas the content of reducing sugars increased correspondingly. The 57,14\% of fructose, $6,78 \%$ of glucose and $7,62 \%$ of sucrose were mainly saccharides in black garlic to answer for its sweet taste.

Antioxidant components, including the polyphenol and total flavonoids contents of BG, increased significantly until $21^{\text {st }}$ day of aging $(p<0,05)$ and correspondingly, the antioxidant activities of BG, measured by DPPH, ABTS, FRAB, and reducing power assays, were highest on the $21^{\text {st }}$ day of aging (Sook et al., 2014). Aged black garlic extract (ABGE) which has the strongest antioxidant effects among garlic extract. Among the five black garlic fractions extracted by chloroform and methanol mixed at different ratios, F3 and F4 showed the strongest antioxidant activities in a DPPH system. Seven substances were purified from F3 and F4 are DL-Lactic acid, 5hydroxymethyl-2-furfural, adenosine, uridine, (1S,3S)-1 methyl-1,2,3,4-tetrahydro- $\beta$-carboline3-carboxylic acid, (1R,3S)-1 methyl-1,2,3,4tetrahydro- $\beta$-carboline-3-carboxylic acid and 2Acetylpyrrole (Table I).

\section{ACTIVITY PHARMACOLOGY \\ Antioxidant effect}

Sasaki et al., (2007) compare activity antioxidant extracts fresh garlic and black garlic from Japanese and Chinese using DPPH (Table II). Potency antioxidant aged black garlic extracts both countries increased, even activity aged black garlic extracts Japanese reached 28-fold more compared with that of fresh garlic.

Jeong et al., (2016) reported the antioxidant capacity extract ethanol 70\% fresh garlic and aged black garlic using four different approaches; exhibited increased the electron-donating ability, ferricyanide reducing power and hydroxyl radical scavenging activity. At a concentration of 0,2 $\mathrm{mg} / \mathrm{mL}$ and $2 \mathrm{mg} / \mathrm{mL}$, the aged garlic extract exhibited a marked increase in the electrondonating ability 2-fold more than fresh garlic. Then, the ability reducing the power of black garlic $0,2 \mathrm{mg} / \mathrm{mL}$ and $2 \mathrm{mg} / \mathrm{mL} 7$-fold more than fresh garlic, even reducing the power of fresh garlic at 2 $\mathrm{mg} / \mathrm{mL}$ is $0,43 \pm 0,01$ similar with the black garlic at a lower concentration of $0.2 \mathrm{mg} / \mathrm{mL}$ is $0,42 \pm 0.00$ (Table III).

Lee et al., (2009) determined the antioxidant effect in vivo of garlic and aged black garlic, an animal model of type 2 diabetes that shows insulin resistance, hyperglycemia, and obesity. Consumption of aged black garlic significantly increased insulin levels, decreased serum glucose, decreased homeostasis model assessment for insulin resistance (HOMA-IR) and decrease serum glucose levels than garlic. 


\section{Novitaria Sembiring}

Table I. Structure Compound Black Garlic (Liang et al., 2015 and Zhang et al., 2015)

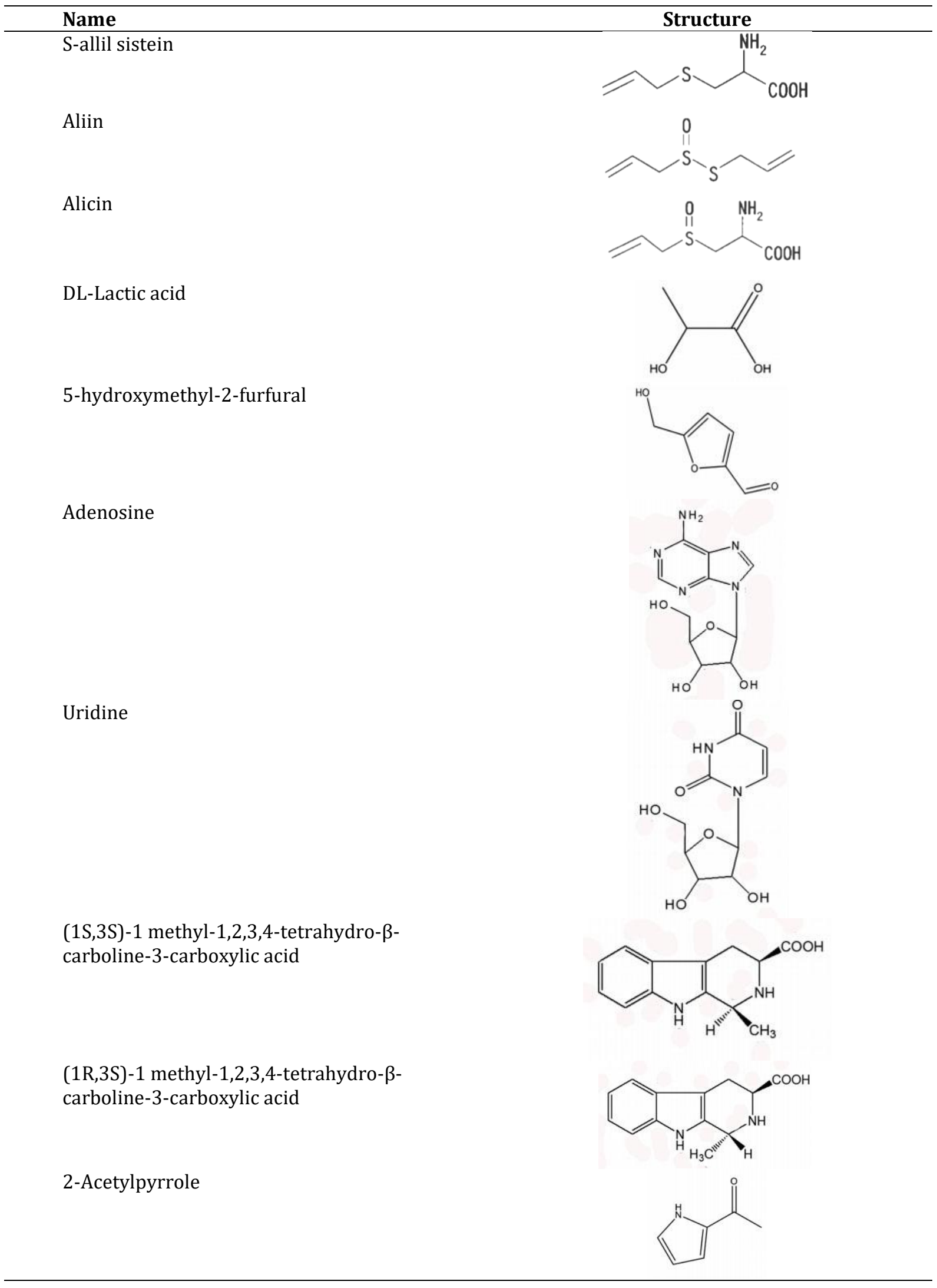


Table II. Activity antioxidant black garlic every country (Sasaki et al., 2007)

\begin{tabular}{ll}
\hline Sample & $\mathbf{R S 5 0 \%} \mathbf{0}^{\mathbf{a}}$ \\
\hline Aged black garlic & \\
Japanese & 4,1 \\
Chinese & 7,3 \\
Fresh garlic & \\
Japanese & 114,9 \\
Chinese & 88,5 \\
\hline
\end{tabular}

an $\mathrm{mg}$ used to reduce $50 \%$ of 1,1-diphenyl-2-picrylhydrazzy

Table III. 1,1-diphenyl-2-picrylhydrazyl and hydroxyl radicals scavenging activities, ferricyanide power and ferrous ion-chelating ability of fresh garlic and aged black garlic extracts (Jeong et al., 2016.

\begin{tabular}{|c|c|c|c|c|}
\hline & \multicolumn{2}{|l|}{ Fresh garlic } & \multicolumn{2}{|c|}{ Aged black garlic } \\
\hline & $0.2 \mathrm{mg} / \mathrm{mL}$ & $2 \mathrm{mg} / \mathrm{mL}$ & $0.2 \mathrm{mg} / \mathrm{mL}$ & $2 \mathrm{mg} / \mathrm{Ml}$ \\
\hline Electron-donating ability (\%) & $8.70 \pm 0.34$ & $35.10 \pm 0.66$ & $19.79 \pm 0.22$ & $82.53 \pm 0.47$ \\
\hline Reducing power (OD $700 \mathrm{~nm}$ ) & $0.06 \pm 0.02$ & $0.43 \pm 0.01$ & $0.42 \pm 0.00$ & $2.60 \pm 0.01$ \\
\hline$(-\mathrm{OH})$ scavenging ability $(\%)$ & $24.45 \pm 0.22$ & $60.72 \pm 0.20$ & $60.85 \pm 0.36$ & $74.95 \pm 0.68$ \\
\hline $\mathrm{Fe}^{2+}$ chelating ability (\%) & $46.04 \pm 0.94$ & $30.62 \pm 1.35$ & $29.54 \pm 1.15$ & $18.24 \pm 0.86$ \\
\hline
\end{tabular}

\section{Anti-Cancer Activity}

Dong et al., (2014) reported aged black garlic extracts (ABGE) may regulate the function of the PI3K/Akt pathway through upregulating PTEN and downregulating Akt and p-Akt expression, as well as suppressing its downstream target, $70-\mathrm{kDa}$ ribosomal protein S6 kinase 1, at the mRNA and protein levels. The HT29 cells growth inhibition rate at $A B G E$ concentrations of 20,50 , and 100 $\mathrm{mg} / \mathrm{mL}$. ABGE inhibited the growth and induced apoptosis in HT29 cells through the inhibition of the PI3K/Akt pathway. Numerous studies demonstrated that allicin, an organosulfur compound obtained from garlic, has the ability to promote the apoptosis of tumor cells, cause cell cycle arrest and improve the antioxidant activity. Qian et al., (2004) reported the tumor cure rate by black garlic water extracts attained 50\% against Meth A fibrosarcoma of BALB/c mouse by intratumor injection of $1 \mathrm{mg}$ extracts, three times every other day. By contrast, fresh garlic extracts (FGE) used as a reference, failed to induce tumor-free animals, even though the reduced tumor size to $60 \%$ to compare with the tumor mass in a nontreated control mouse. That garlic organo-sulfur compounds test (5-100 $\mu \mathrm{M})$ worked to protect against DNA damage (Belloir et al., 2006). Park et al., (2014) reported U937 cells were exposed to various concentrations of hexane extract aged black garlic (HEABG) for $24 \mathrm{~h}$ or 10 $\mu \mathrm{g} / \mathrm{mL}$ of HEABG for the indicated times. The MTT assay was used to examine the effect of HEABG on cell viability. Resulted showed that the viability of HEABG-treated cells decreased in time and concentration-dependent manners. Consistent with these effects, after treatment with HEABG, U937 cells showed changes in morphology, including blebbing of the cell membrane and shrinkage of the cells, in a time-dependent manner. HEABG-induced apoptosis signaling pathway in human leukemia U937 cells. First, the death receptor-mediated extrinsic pathway is initiated by ligation of the transmembrane death receptor to activate effector caspases, such as caspases-3. Second, the mitochondrial membrane, which induces activation of caspase-9, and thereby initiates the apoptotic caspase cascade. Gastric cancer is one of the most common human malignant tumors. Epidemiological investigations have provided evidence that gastric carcinogenesis is a complex, multistep and multifactorial event (Nagaoka et al., 2009). Wang et al., (2012) reported that ABGE treatment inhibits the growth of SGC7901 cells by inducing apoptosis in vitro. Flow cytometry (FCM) with PI staining revealed that the apoptosis rates of SGC-7901 cell line treated with 10,50 or $100 \mathrm{mg} / \mathrm{ml} \mathrm{ABGE}$ for $48 \mathrm{~h}$ were $10.9 \pm 3.9 \%, 16.7 \pm 4.8 \%$, and $22.7 \pm 5.8$, respectively and were significantly higher than that in the negative control. ROS are also involved in the pathogenesis of gastric malignancies. To date, the correlation between the administration of ABGE and its effect on the status of SOD and GSH-Px has yet to be fully investigated. The activities of SOD and GSH-Px were significantly increased by the administration of ABGE in an animal model.

\section{Hepaprotective Activity}

Wang et al., (2012) report aged black garlic (ABG) caused a significant decrease in the alcohol- 
induced increase in hepatic activities of aspartate aminotransferase, alanine, aminotransferase, alkaline phosphates, and lactate dehydrogenase. ABG treatment significantly decreased the thiobarbituric acid-reactive substances level in the liver, heart, and plasma. Glutathione content and the activities of antioxidant enzymes such as glutathione peroxidase, glutathione reductase, and catalase in liver were significantly enhanced. Furthermore, the oxidative damage to blood lymphocyte DNA caused by chronic alcohol ingestion was significantly decreased in the ET + ABG group. In conclusion, $\mathrm{ABG}$ has strong antioxidative properties and may be a promising agent for protecting against chronic alcoholinduced liver damage.

\section{Enhance the Immune System}

Black garlic activity to increase the immune system was tested by measuring the increase in natural killer (NK) cell, cytokine IFN- ${ }_{\gamma}$, TNF- $\alpha$, and IL-2. 10-day treatment black garlic extract is the maximum time of activated natural killer (NK) cells increased. Cytokines IFN- ${ }_{\gamma}$, TNF- $\alpha$, and IL-2, which were generated from Th1 ( $\mathrm{T}$ lymphocytes helper 1), and NO generated from macrophages reached a maximum 8 days later ( 3 days after ceasing the treatment of the extract), and that of IL-2 6 days later. This indicates that the black garlic extracts worked first on both $\mathrm{T}$ lymphocytes and macrophages to activate them, and cytokines released from these activated cells enhanced the activity of NK cells to attack abnormal cells like tumor cells. Aged black garlic can enhancement of the immune system because have rich SAC than fresh garlic (Wang et al., 2010)

\section{Hyperglycemia and Dyslipidemia Effect}

Seo et al., (2009) reported consumption of aged black garlic (ABG) significantly decreased homeostasis model assessment for insulin resistance (HOMA-IR) and tended to decrease serum glucose. Garlic consumption significantly decreased total cholesterol but did not decrease triglyceride and HDL-cholesterol levels, while aged black garlic significantly reduced serum total cholesterol and triglyceride and increased HDLcholesterol levels. ABG alleviated insulin resistance in $\mathrm{db} / \mathrm{db}$ mice, obese-diabetic animals with insulin resistance. Insulin resistance is an important initiating pathogenic mechanism of type 2 diabetes.

\section{Antiinflammatory Effect}

Kim et al., (2014) aged black garlic extract (ABGE) was weaker than fresh raw garlic extract (FRGE) in inhibition of cyclooxygenase-2 and 5- lipooxygenase activities. FRGE reduced $\mathrm{PGE}_{2}$, NO, IL-6, IL-1 $\beta, \mathrm{LTD}_{4}$, and $\mathrm{LTE}_{4}$ production in LPSactivated RAW 264,7 cells more than did ABGE. Treatment with glucose or fructose inhibited neither the activation of $\mathrm{NF}-\mathrm{kB}$ nor the expression of Inos, COX-2, and IL-1. ABGE has higher component fructose, glucose, sucrose, and main saccharides than FRGE, so anti-inflammatory activity in ABGE lower than FRGE. The anti-oxidant activity of ABGE is not directly proportional to its anti-inflammatory activity

\section{Anti-Allergic Effect}

Kim et al., (2012) reported anti-allergic aged black garlic lower than fresh garlic at concentrations up to $100 \mu \mathrm{g} / \mathrm{mL}$, was analyzed by measuring their inhibitory effects against $\beta$ hexosamine release. A considerably higher suppression of $\beta$-hexosamine release was found in fresh garlic extract at lower concentrations compared with that of the black garlic.

\section{CONCLUSION}

The concentration of S-allyl cysteine (SAC) levels increases due to the fermentation process in black garlic, which has been reported as a good source of antioxidant compounds. It has also potential as inhibits the growth of cancer cells, hepatoprotective, enhance the system immune, hyperglycemia, dyslipidemia, anti-allergic and anti-inflammatory. Black garlic needs further exploration, particularly the mechanics of its biological activity, to be as supplement health.

\section{REFERENCES}

Belloir, C., Singh, V., Daurat, C., Siess, M. H. \& Le Bon, A. M. 2006. Protective effects of garlic sulfur compounds against DNA damage induced by direct- and indirect-acting genotoxic agents in HepG2 cells. Food Chem. Toxicol. 44, 827834.

Dong.M., Guiqing. Y., Hanchen. L., Xiaoxu. L., Sixiang. L., Dongnung. S. \& Yishan. W. "Aged Black Garlic Extract Inhibits HT29 Colon Cancer Cell Growth via the PI3K/Akt Signaling Pathway". Biomedical Reports, vol. 2, no. 2, 2014, pp. 250-54.

Jeong, Y.Y., Ji, H.Y., Jung-Hye. S., Min, J.K., Jae, R.K., Jaehee, H. \& Dawon, K. 2016. Comparison of Anti-Oxidant and Anti-Inflammatory Effects between Fresh and Aged Black Garlic Extracts. Molecules, 21: 1-15.

Kim, J. H., Nam, S. H., Rico, C. W. \& Kang, M. Y. 2012. A comparative study on the antioxidative and anti-allergic activities of fresh and aged black garlic extracts. Int. J. Food Sci. Technol,47, 1176-1182. 
Kim, M.H., Min, J.K., Jeung, H.L., Jang, I.H., Jin, H.K., Dai-Eun, S. \& Mee, R.K. 2011. Hepatoprotective Effect of Aged Black Garlic on Chronic Alcohol-Induced Liver Injury in Rats. Journal Of Medicinal Food, 14:732-738.

Kim, M. J. Yoo, Y.C., Hyun, J.K., Suk, K.S., Eun, J.S., AYoung, M., Nak, Y.S., and Mee, R.K. 2014. Aged black garlic exerts anti-inflammatory effects by decreasing NO and proinflammatory cytokine production with less cytoxicity in LPS-stimulated RAW 264.7 macrophages and LPS-induced septicemia mice. J. Med. Food. 17, 1057-1063.

Lee, Y.M., Gweon, O.C., Seo, Y.J., Im, J., Kang, M.J., Kim, M.J., and Kim, I. K. 2009. Antioxidant effect of garlic and aged black garlic in animal model of type 2 diabetes melitus. Nutrition Research and Practice, 3, 156-161.

Liang. T., Wei. F., Lu. Y., \& Kodani. Y. 2015. Comprehensive NMR analysis of compositional changes of black garlic during thermal processing. J Agric Food Chem, 63: 683-691.

Lu, X., Li, N., Qiao, X., Qiu, Z. and Liu, P. 2017. Composition analysis and antioxidant properties of black garlic extract. J. Food Drug Anal. 25, 340-349.

Moelyono MW. Etnofarmasi. Deepublish, Yogyakarta, 2014, pp. 42, 149, 156, 163.

Nagaoka, I., Kaori, S., Taisuke, M., Francois, N., Hirosi, T and Michimasa, H. "Evaluation of the Effect of Alpha Defensin Human Neutrophil Peptides on Neutrophil Apoptosis". International Journal of Molecular Medicine, vol. 23, no. 4, 2009, pp. 521-27.

Park. C., Sejin. P., Yoon. H.C., Gi-Young. K., Young. W.C., Byung. W.K. and Yung. H.Y. 2014. Induction of Apoptosis by a Hexane Extract of Aged Black Garlic in the Human Leukemic U937 Cells". Nutrition Research and Practice. 8 (2), 132-37.
Qian, Y., Corum, L., Meng, Q., Blenis, J., Zheng, J,Z, Shi, X., Flynn, D,C., and Jiang, B.H. 2004. PI3K induced actin filament remodeling through Akt and p70S6K1: Implication of essential role in cell migration. Am. J. Physiol. - Cell Physiol., 286, 153-163.

Sasaki, J., Chao, L., Machiya, E., Takahashi, M. \& Hamada, K. 2007. Processed Black Garlic (Allium sativum) Extracts Enhance AntiTumor Potency against Mouse Tumors. Glob. Sci, 2007, Books 4-7.

Seo. Y-J., Oh-Cheon. G., Jieun. I., Young-Min. L., MinJung. K. \& Jung-In. K. 2009. Effect of Garlic and Aged Black Garlic on Hyperglycemia and Dyslipidemia in Animal Model of Type 2 Diabetes Melitus. J Food Sci Nutr.14:1-7.

Sook, Cha, H. S. and Lee, Y. S. 2014. Physicochemical and antioxidant properties of black garlic. Molecules. 19, 16811-16823.

Tran, G. B., Dam, S. M. and Le, N. T. T. Amelioration of Single Clove Black Garlic Aqueous Extract on Dyslipidemia and Hepatitis in Chronic Carbon Tetrachloride Intoxicated Swiss Albino Mice. Int. J. Hepatol, 2018.

Wang, D., Yonghui, F., Jun, L., Jianzhong, Y., Meiru, W., Jin-ichi \& Changlong, L. 2010. Black Garlic (Allium sativum) Extracts Enhance the Immune System. Medicinal and Aromatic Plant Science and Biotechnology 4(1), 37-40.

Wang, X., Fei, J., Qin-Wen, W., Juan, W., Ke-Yang., Rong-Rong, H., Han-Chen, L., Hong-Yang, W., and Yi-Shan, W. 2012. Aged Black Garlic Extract Induces Inhibition of Gastric Cancer Cell Growth in Vitro and in Vivo. Molecular Medicine Reports 5 (1), 66-72.

Zhang, Z., Mengmeng, L., Rui, L., Yunfeng, G., Mengying, X. and Min, Z. 2015. Evaluation Of Alliin, Saccharide Contents and Antioxidant Activities Of Black Garlic During Thermal Processing. Journal of Food Biochemistry.P:1-9. 